\title{
A Failure in 'Designed Citizenship': A Case Study in a Minority-Han Merger School in Xinjiang Uyghur Autonomous Region
}

\author{
LIN Y I \\ Xiamen University, China \\ yilin911@gmail.com
}

\begin{abstract}
Drawing upon the theses of State racism (Michel Foucault), homo sacer (Giorgio Agamben), and safe citizenship (Cynthia Weber), and fieldwork data collected from a multiethnic primary school in Xinjiang, this paper examines the way in which the state agencies of the local government, the school and mainstream citizens design citizenship for Uyghurs, and how Uyghurs interpret and act upon their citizenship. The findings show why, and how, designed citizenship by the mainstream system for Uyghurs has failed to produce a desirably productive force for the prosperity of both the Uyghur community and society at large. The findings require reconsideration of what could be a win-win citizenship for both the state and the citizen.
\end{abstract}

\section{Introduction}

China has 55 officially identified ethnic minority groups. The modern education of ethnic minorities has long been recognized as different from ordinary education in Chinese Han-dominated regions. With more than 60 years' development since the Chinese Communist Party (CCP) came to power in 1949, minority education has been to a large extent systematized, with various levels as well as forms of schooling for ethnic minority people. In the Party-state's attempt to realize its goals for minority education, special policies are at the center of the official agenda. The issues these policies are concerned with include, among others, bilingual education and college entrance examinations. As an important means of promoting bilingual education, an increasing number of schools of ethnic minorities and those of ethnic Han Chinese have been merged to become minority-Han merger schools (Min-Han hexiao) in Xinjiang Uyghur Autonomous Region (XUAR), which has featured new developments for minority education in the region. 
A working conference with a theme of the management of multiethnic schools was held in Yining City of XUAR in August 2012, and 'Suggestions on Further Strengthening the Management Work of Merger Schools Among Ordinary Secondary and Primary Schools (Draft)' (hereafter 'the Draft') was issued at the conference. The Draft particularly addresses three primary targets of the merger school, these being: (1) the maintenance of ethnic unity and social stability; (2) the promotion of economic and social development of Xinjiang via the cultivation and training of high quality talents and laborers; and (3) planting the idea of ethnic unity in the minds of younger generations. These targets show a serious concern from the local government with the management of its population, the key issue affecting '(in)security' in the modern state. The main driving force behind this concern, from a Foucauldian perspective, is that the population in modern history becomes the source and the root of the state's power and wealth (2009: 68-9). Therefore, contrary to the conventionally disciplinary government that tends to deny citizens' desires, the modern state needs to say 'yes' to its citizens to activate and maximize this fundamental resource (Foucault, 2009: 73-4).

Population varies with physical, economic, institutional, moral, and religious conditions, and associated conduct. As a consequence, 'what government has to do with is ... a sort of complex composed of men and [related] things', ranging from wealth, climate, to customs and habits, ways of acting and thinking, and accidents and misfortunes (Foucault, 1991: 93). The state needs to analyze and predict trends among its population by differentiating the latter hierarchically into various groups to enable it to design technologies with respect to the management of these different groups (Foucault, 2009: 73-4). This is the very basis on which State racism emerges; it is not merely connected with biology per se, but refers to a combination of the social, economic, and cultural dimensions of different groups. For Foucault, State racism, based on the ideas of natural selection and the struggle for existence, contends that the existence of other inferior (degenerate or abnormal) races is a biological threat posed towards one's own superior (healthy and pure) race. It is hence necessary to eliminate (or improve) other races to secure the safety of one's own race and to make it healthier and purer (Foucault, 2003: 255-7). Eventually, 'the species and the individual as a simple living body become what is at stake in a society's political strategies', and sovereign power 'is then gradually transformed into a "government of men"' 'through the most sophisticated political techniques' (Agamben, 1998: 3). This brings a new way of government, governmentality, a combination of technologies of power and technologies of the self (Foucault, 1988: 18). Governmentality is a way of government of men from both within and without that connects life with politics, and consequently leads to the emergence of the concept of 'biopolitics'.

Inspired by the idea of biopolitics, Agamben argues that natural life is inscribed in the juridico-political order of the nation-state at the very moment when the state declares that every man is born with sacred and inalienable rights and freedoms (Agamben, 1998: 127-8), that is citizenship. As a result, when the state feels threatened and it is necessary for it to take emergency measures to protect the people and the state, 
the law concerning the rights of citizens may be suspended in the name of a state of exception (ibid.: 166-8), which could eventually turn the citizen into 'bare life' or 'homo sacer', having lost both rights and protection. This is the very foundation on which all sorts of camps tackling exceptional situations come into being (the concentration camps of the Nazis was a most extreme case), and moreover are routinized to a large extent by the modern state, so that it has resulted in a camp-like pattern of government (ibid.: 74-6). Thus, 'all law is "situational law"' (ibid.: 16). Agamben is hence highly suspicious of the contractual state/citizen relationship, in which political communities are grounded in something like a 'belonging' (ibid.: 181).

Similarly concerned with the issue of safety, Cynthia Weber suggests that what concerns the sovereign power of the state most is to design a safe relationship between citizens, states, and violence. Different from Foucault's positive view of the modern state, Weber argues that the citizen/violence relationship is inherently unsafe for both the state and citizens, because

From the state's point of view ... citizens challenge both the state's claim to hold a monopoly on the legitimate use of violence and a monopoly on the legitimate interpretation of the citizen/violence relationship. From the citizen's point of view ... the state's offer of protection to citizens in exchange for their commitment to become agents of violence for the state means that the state both protects and endangers citizens. It presumably protects them when it gives them security, and it endangers them when it demands security from them. (Weber, 2008: 126)

For Weber, the conventional idea of design is aimed at solving problems with invented objects or systems to make the world function more smoothly. In this light, 'design is a discourse of legitimation. Claims to specific designs and designers authorize all sorts of other claims - to value and status, to health and happiness, and to safety and security' (Weber, 2008: 127). This is the way the state designs citizenship that aims to guarantee the safety of the state, and is termed by Weber as 'safe citizenship'. However, Weber does not think that the state can entirely hold control over the citizenship it has designed (ibid.: 128). Weber's concern with the state/society relationship corresponds to her emphasis on what the concept of citizenship does over what it is (ibid.: 129). This is also the implication that Foucault's technologies of power and the self-that focus upon conduct - have for our understanding of the concept of citizenship. Following Foucault, Ong (1996) portrays (cultural) citizenship as a dual process of 'being-made' and 'self-making', where both the social system and individual citizens play their part in citizen-making. Isin connects relationship with conduct in his definition of what he terms 'activist citizenship':

Citizenship is a dynamic ... institution of domination and empowerment that governs who citizens ... are and how these actors are to govern themselves and each other in a given body politic. Citizenship is not membership. It is a relation that governs the conduct of (subject) positions that constitute it. (Isin, 2009: 371) 
Informed by the literature reviewed above, and to partially borrow Calhoun's (Calhoun et al., 2012: 328-30) interpretation of Bourdieu, we define citizenship as reflexive acts in a field that generates a set of power-relation-grounded social positions, and supports the practices associated with them. More importantly, acts are not merely a reflection of established positions, but also the result of many contending projects of (new) position-taking. These contending position-taking projects are essentially what Isin terms rupture of acts (Isin, 2009: 377-83). By these he (ibid.: 379) means acts that create a scene rather than following a script, thus making a difference by breaking 'routines, understandings and practices'. He views these make-a-difference acts as activist citizenship.

This paper examines the state/Uyghur relational framework designed via policy and practice of the merger school in Xinjiang, and the impact on Uyghur citizenship practice. Neither the Han Chinese nor the Uyghur are merely seen as a biologically or culturally distinct group from one another as the concept of race or ethnic groups (minzu) conventionally connotes. Their differences, as the article will show based on Foucault's thesis of State racism, are comprehensively associated with social, economic, and cultural dimensions of a given group, that bring about different biopolitics for different groups. In what follows, we firstly uncover the safety logic and strategies of this citizenship design, followed by an examination of its consequences. Towards the end of the paper, the implications of our findings for new thinking on citizenship are sketched.

\section{Merger schools: trajectory and scholarship}

Merger schools in Xinjiang were specifically designed in the 1950 s to cater for the children of small-sized ethnic minority groups inhabiting ethnically mixed districts, and had become a popular form of minority education by the 1980s. However, to redress a tendency towards the elimination of minority cultures in the course of merger schools, the state re-introduced the policy that encouraged the establishment of (more) minority schools in minority areas. This led to a short period of decline (to dozens) of merger schools in the mid-1980s, a trend that was soon altered in the 1990 os by a new policy of school mergers to integrate and more wisely spend resources ( $\mathrm{Li}, 2001)$. On entering the twenty-first century, the provincial government encouraged further school mergers, and merger schools were increased from 461 in 2001 to more than 1,100 by $2013 .{ }^{1}$

In the Draft, the merger school is defined as an educational form in which majority and minority students are either divided into different teaching classes, or mixed into the same classes, the language of instruction being adopted accordingly. It further pronounces the significance of the merger school:

The implementation of the merger school is ... a significant initiative of scientifically enhancing minority education, and a reflection of an

\footnotetext{
1 Sources are from the Draft.
} 
equal, united, mutually supportive and harmonious socialist new type of ethnic relationship in education. Both the merger school and bilingual education are significant for sentiment communication between ethnic groups, reinforcement of ethnic contact and connection, promotion of ethnic unity, and realization of the long-term peace and stability and leapfrog development of Xinjiang.

This articulation of the merger school reflects a primary concern among government officials about safe citizens, a precondition of socioeconomic development, the same driving force behind the establishment of the Inland Xinjiang Boarding Class (Neidi Xinjiang Ban) (Chen, 2008; Grose, 2010, 2015). Like the Xinjiang Class, the merger school itself has become an important route by which the state designs and implements safe citizenship at the grassroots level.

In spite of its increasing significance and number, the merger school as a new subject has drawn limited attention from academia. ${ }^{2}$ Fewer studies further identify the factors that influence ethnic communication in education (Tsung, 2014; Wang, 2010; Zuliyati, 2008, 2014). Nonetheless, in this paper we understand citizenship as a relationship by deciphering the state/citizen relationship, against which we believe ethnic relations are formulated. This state/citizen relationship has direct influence on the mentality and behaviors of different ethnic groups as our case study will show. This approach to citizenship is rarely seen in the scholarship examining ethnic relationships or economic inequality between the Uyghur and Han in XUAR. ${ }^{3}$

\section{Field setting and methods}

Our case school is located in District T, one of the seven districts of the old town of Urümchi, the capital city of XUAR, and the political, economic, cultural, and financial center of Urümchi. The Han Chinese are the largest ethnic group in Urümchi, accounting for $74.91 \%$ of the population; they are followed by the Muslim Uyghur at 13\% (Urümchi Statistics Bureau, 2011). Wang (2000: 48) suggests that Urümchi was characterized by ethnically residential segregation in its old town in the 1990s, on account of cultural-historical tradition. In its new town, where public sectors were concentrated, a mixed residential pattern was observable to a certain degree. This residential segregation pattern in the old town largely remains the same today: Uyghurs primarily inhabit Districts T and S of the town, and Han Districts X and S. After the ' $7 / 5$ ' event in July 2009 that involved a series of violent riots over several days, when over one hundred Han and Uyghurs were killed whilst over 1,00o Uyghurs were arrested and detained, ${ }^{4}$ the residential segregation became even more clear-cut, that is, was further widened. With the North Gate of the city as the 'borderline', Uyghurs are now

\footnotetext{
2 For example, Ba (2006), Jiang (2002), Li (2001), Zhang (2005).

3 For instance, Abdureşit Jelil and McMillen (2011), Cliff (2012), Grose (2010), Han (2010), Hao and Liu (2012), Ma (2012), Qian (2009), Smith (2002), Tsung (2014), Yee (2005), Zang (2011).

4 See the special issue of Central Asian Survey (2009), 28(4).
} 
concentrated on the southern side of the Gate, and Han Chinese on the northern side. In other words, although Uyghurs have consciously segregated themselves from Han Chinese since at least the mid-1990s (Bellér-Hann, 2002; Smith, 2002), this conscious segregation worsened after the 2009 riots.

Ethnic minorities account for $39.11 \%$ of the population in District T. 5 According to the provincial statistics of the sixth census of China, $\mathrm{T}$ is one of the districts with the highest proportion of Uyghur migrants. The minorities are especially concentrated in its four sub-districts, where they make up $65 \%$ of the whole population, and the minority migrants make up $70.2 \%$ of the migrant populace. Wang (2011) discovered that the populace in this district is characterized by a high proportion of minority migrants with low income, poor living conditions, low educational levels, and a high dropout rate amongst their school-aged children.

Our case-study school was the result of a merger between two primary schools, Q and $\mathrm{W}$, in 2004, with $\mathrm{W}$ as the new school name. School W had been predominantly Uyghur before the merger whilst School Q had been Han Chinese. The new school had two campuses: the main campus of $\mathrm{W}$, and the branch campus of Q. The school was divided into two departments, that of Han Chinese and the minority. By September $2009,{ }^{6}$ the school had in total 56 teaching classes, with the 12 classes of the Chinese department located on the branch campus, and the 44 classes of the minority department on the main campus. There were in total 3,214 students, with 462 in the Chinese department and 2,752 in the minority department. Migrant students amounted to $52 \%$ of the whole student body, with $70 \%$ Uyghur migrant children living in District T. The school had 129 permanent teachers ( 15 in the Chinese department and 114 in the minority department), and 92 contracted teachers (22 in the Chinese department and 70 in the minority department).

As is the case elsewhere in China, minority students in Xinjiang who sit examinations in their ethnic language for entry to the minority school are of minkaomin (hereafter MKM). They usually receive education in their own ethnic language from the beginning of their schooling. Those who sit examinations in the Chinese language for entry to the regular Han Chinese school are of minkaohan (hereafter MKH), who usually receive education in Chinese from an early stage of their schooling. The majority of Uyghur teachers and MKM Uyghur students made up the major body of the main campus, and Han Chinese teachers and Han Chinese, Hui, and MKH Uyghur students were largely concentrated on the branch campus. Meanwhile, the school also sent 295 Uyghur MKM students of Grade Five (six classes) from the main campus to the branch campus to study for one school year of 2011/12. The ethnic composition of the students on the branch campus was as follows (see Table 1):

5 The data are from the government website of Tianshan District, Urümchi City, XUAR. See http://www.xjtsq.gov.cn.

6 This is the newest information we could get from the school official at the time of our investigation. 
Table 1. Ethnic composition of students at school $W$ in Üümchi

\begin{tabular}{llllllll} 
& & \multicolumn{2}{c}{ Uyghur } & & & \\
\cline { 3 - 4 } Ethnic group & Han Chinese & MKM & MKH & Hui & Others & Total \\
\hline Student number & 194 & 295 & 103 & 91 & 11 & 694 \\
Percentage & 27.95 & 42.51 & 14.84 & 13.11 & 1.59 & 100 \\
\hline
\end{tabular}

The Uyghur was the largest student body, with the majority being of MKM. Our fieldwork was carried out from September 2011 to January 2012, with a follow-up investigation in September and October 2012. Besides the collection of government and school documents, we observed classes respectively in the minority department $(36$ hours) and the Chinese department (30 hours) between September 2011 and January 2012. In the meantime, we interviewed 47 students (16 Han Chinese, 16 MKM Uyghur students, and $15 \mathrm{MKH}$ Uyghur students), 24 teachers and/or school administrators (11 Han Chinese teachers, two administrators of the Chinese department, nine Uyghur teachers, and two administrators of the minority department), and 14 parents of either Han (9), or Uyghur (three MKM, two MKH). Nonetheless, given the sensitivity of our research topic, it was not always easy for us to carry out fieldwork even though we knew the headmaster - our gatekeeper - personally (which indeed significantly facilitated our fieldwork in the school). For example, sometimes some Uyghur teachers answered our questions with some caution. Even so, as demonstrated below, we were generally satisfied with the rich and nuanced data we collected, which matched our expectations.

\section{Merger school policy: the message behind the scene}

The principles of the development of the merger school are detailed in 'The Decision of XUAR Party Committee and Government on Vigorously Promoting Bilingual Education' issued in 2004. It prompts minority-concentrated regions to establish merger schools. Meanwhile, it calls for an expansion of regular Han Chinese schools to encourage minority students to attend them. Article 19 particularly urges that 'schools of all levels and all kinds should maximize the role bilingual education plays in reinforcing motherland consciousness and identification with the Chinese Nation, and strengthening national unification and ethnic unity, among students'. These principles are the three primary targets of the merger school in the Draft, which emphasize the cultivation of younger generations to become both upholders of social stability and human resources for economic development. These targets are very similar to those of the Xinjiang Class scheme that Chen (2008) and Grose (2010, 2015) have observed.

A number of corresponding measures are designed to meet these targets, primarily focusing on fostering a safe ethnic relationship as the precondition of economic prosperity. These can be summarized as three points. Firstly, students and teachers from diverse ethnic communities should respect, learn from, tolerate, and appreciate 
each other. Among others, to learn the history, culture, customs, and languages of other ethnic groups is the important basis for enhancement of mutual understanding. Secondly, all teachers and students should downplay ethnic consciousness whilst cultivating individual identity. Lastly, all schools and their teachers have a political duty to provide ideological education to students on Marxist atheism; they should promote unity, harmony, and stability to enable teachers and students of all ethnic groups to integrate as a whole, ideologically, mentally, and culturally.

On looking into these principles, targets, and measurements, contradictions become apparent. Firstly, the document emphasizes the importance of learning and understanding other cultures, on the one hand, and, on the other, prioritizes the education of Marxist atheism. Therefore, it is in fact a one-way accommodation by the secularization of religious communities. Secondly, to oppose ethnic consciousness against individual identity is to view individual identity as being created in a cultural vacuum, rather than being substantively grounded in certain cultural context(s). Thirdly, it encourages an expansion of education in Chinese among minority students, and bilingual education exists merely in name to a large extent. All of these contradictions in the policy reveal the inherent logic of the merger school: keeping the politically correct voice de jure whilst denying de facto the legitimate status of minority languages, cultures, and identities.

This denial of minority languages, cultures, and identities is rooted in the view of them as being less valuable for socioeconomic development, or needing to be restricted or excluded to make a safe environment for social development. This is an idea of State racism, that presumes that one's own (the mainstream) race has acquired, and consequentially possesses, a set of universal (healthy or productive) standards. These standards will necessarily be extended to eventually improve the 'other race' (the ethnic minority in this case) by transforming the latter to 'non-other'. For Foucault (2003: 62), this State racism is one that 'society will direct against itself, against its own elements and its own products. This is the internal racism of permanent purification, and it will become one of the basic dimensions of social normalization.' This State racism is examined in detail through our case study below.

\section{Merger school W: a failed design?}

Since the merger in 2004, School W sent a group of MKM students of the minority department from the main campus to the branch campus every school year to study alongside the Chinese department students to showcase ethnic unity, and vice versa. Meanwhile, the idea of ethnic unity was reflected in the arrangement of the school space. Banners, posters, pictures, or stories that promoted ethnic unity were hung on school walls or put up on blackboards. They included such banners inscribed by 'Fifty Six Ethnic Groups and Fifty Six Flowers', the most promoted song by the political mainstream that chants ethnic unity. They also included illustrations such as teachers of different ethnic groups sitting together to communicate about teaching methods, and students of various ethnic groups discussing their studies together. The idea was 
further reified in the attempt of officials to create a school culture of 'Three Togethers' (sange zai yiqi): minority and Han teachers work together, minority and Han students study together and play together. These were not merely propaganda of the school but also requirements set for teachers and students to meet. For example, we found on the office wall of some Han teachers their written promise: '[I] will never say anything that jeopardizes ethnic unity, and [I] will never do anything that jeopardizes ethnic unity.' As a consequence of this inculcation, students were also accustomed to the discourse of ethnic unity. A Han student, who chaired a school activity, put it in this manner:

All activities of our school are [designed] for ethnic unity. During the sports meeting when we went to the main campus, my address was: we are one family, our country is one big China; the harmonious family will lead to prosperity of all things, including you and me. We should unite as a whole, help each other.

The painstaking promotion of ethnic unity revealed a deep concern among school officials about the reality that teachers and students of Uyghur and Han groups were in fact not 'together'. This 'not-together' scenario was easily observable in various teachers' gatherings. One of these occasions was the end-of-year dinner party. To accommodate Uyghur Muslim colleagues, the school organized the party in the Uyghur restaurant offering halal food and a Uyghur dancing and singing performance. Han teachers would usually be deeply disappointed because they 'do not like such a noisy [not very "civilized"] place'. Yet, the school officials, despite an awkward feeling when organizing such activities, would never approve that Uyghur and Han teachers have separate parties because of a concern for the image of ethnic segregation this may create for their higher authorities. As a consequence, Uyghur and Han teachers chose to sit in different areas next to their own ethnic group at the dinner party, and there was no form of interaction between them.

Another illustrative example was at the New Year performance party. A Han teacher portrayed the situation in this way:

Every time when our school organizes an activity, if minority and Han are put together, that would definitely make us feel awkward. Since this is a merger school, you should allow for the Chinese language [to be used], you should also allow for all other languages [to be used], shouldn't you? But all the performances minority teachers offered would be in the Uyghur language; moreover, Han teachers are sitting here, and Uyghur teachers are sitting there, so we are separated ... They do not pay attention to each other. When it comes to the Uyghur performance time, all is in Uyghur. We Han teachers only care about chatting between us. We do not understand [Uyghur], and nor would we care to. When it comes to the Han performance time, minority teachers would not like to pay attention either. If some would like to listen to it for a minute, they do it; those who would not like to simply entertain themselves. No way [for us] to have a feeling of being together.

One Han teacher summarized this scenario as such: '[W]e do not have a shared communicative language, nor do we have shared interest in the same topics.' 
Meanwhile, to reduce 'unnecessary' conflicts and troubles, both Uyghur and Han teachers would require that their co-ethnic students follow an 'out-of-touch' rule in their dealing with students of the other group. A Han teacher explained this as such:

After the merger, [our students] often have troubles with students of minority classes. [They] are often bullied by Uyghur students. I am very angry. We cannot separate them in a fight. The only thing I can say [to our student] is that 'you make a detour next time when you see them'. We are bullied; all we can do is to blame our own children: 'why did you not avoid them as far as you can?'. The school says, if there is an issue, find out problems of your own (ethnic) kids.

And a Uyghur teacher put it this way:

Our minority department students would not sit quietly. They like pushing [with fellow students]. No shared language [with Han students]. You kick me and I push you, it is [sometimes] difficult to avoid someone [kicking or pushing] a little bit too hard. So I told minority students: 'do not have contact with them [Han students], try not to offend them'.

To our surprise, the school officials seemed to discourage ethnic unity at a certain level. They segregated the Uyghur from the Han in arrangements of space and curriculum, a way of institutionalizing ethnic segregation. For example, all the offices of the minority department teachers were arranged on the first floor of the office building, and those of the Chinese department were situated on the second and third floors. The two blocs of teachers rarely had communication or contact apart from in school meetings, which all teachers were required to attend in the same room. Meanwhile, the previous two schools, W and Q, still separately managed their curriculum. For example, in spite of the same textbooks being adopted by the two departments, the Chinese department was required to finish two volumes every year, whereas the minority department was only assigned one. This pedagogy was a major barrier separating the Uyghur from the Han, as a Han teacher assessed in this way:

The most serious problem with the merger school is polarization [liangji fenhua]. In spite of the name of merger school, [in reality] minority is minority, Han is Han, no way to melt together, very difficult to melt together. Nobody wants to try.

Having separated minority people from majority people either institutionally or situationally, both school officials and ordinary teachers explicitly showed their reluctance towards ethnic unity, although, in a politically correct fashion, officials would be highly cautious of any ethnic segregation. ${ }^{7}$ This dilemma that the school was caught in when handling ethnic relationships is deeply ingrained in its concern with a key element: safety. On the one hand, it was worried that ethnic segregation would violate state policy, and at the same time bring hard-to-predict difficulties or risks to

7 In fact, social segregation between the Uyghur and the Han Chinese can be found across the wider society. For more information, see Smith (2002), Smith Finley (2013). 
school management. On the other hand, it was a concern that possible resistance from, or conflicts between, the two sides would occur if the school forcefully put Uyghur and Han together. Not by coincidence, a similar discouragement of ethnic integration has been observed in the Xinjiang Class, in spite of its primary aim being paradoxically directed at ethnic unity (Chen, 2008). On the surface, it seems that the school did not find a proper way for Han and Uyghur to harmoniously share the same space. Fundamentally, this is because the way in which it governed its multiethnic populace was driven by its pursuit of school safety, largely guided by the civilizing projects of State racism, as shall be detailed later on. Under this ideological framework, the productive force that would supposedly be the source of societal strength is not the diversity of men and related things Foucault presumes. Instead, the school mainstream saw Han, the race and the conveyor of Han civilization, as the only legitimate productive force. Other races would be regarded as a non-productive or harmful force before it was 'purified' into the race. This has largely reduced governmentality of two dimensions of technologies (Foucault, 1988:18) to one dimension of technologies of power, where there is limited room or source for minority citizens to attain wellbeing beyond submission to domination. As a result, passivity in relation to, or disengagement from, the mainstream, became the dominant strategy of Uyghur students and teachers.

\section{Education for 'purification': from curriculum, discourse to practice}

The most important message hidden behind 'difference' is the hierarchy of superiority $v i s-\grave{a}$-vis inferiority: the population that state power controls is subdivided into different races and treated as such (Foucault, 2009: 255). Inferior races are always thought to be potentially an unsafe element, harmful to societal prosperity, and thus in need of purification. Foucault (1978: 120) argues that, in the seventeenth and eighteenth centuries, when governmentality gradually came into being its techniques were firstly applied to the socioeconomically privileged and dominant bourgeois. For Foucault, it was by writing its own history as the nation capable of sustaining and enhancing the life of the species-being among other nations within the state that the bourgeois established its own role as the subject of history. This historically significant role was played out by 'its ability to administer itself, to manage, govern, and guarantee the constitution and workings of the figure of the state and of state power' (Foucault, 2009: 221-3). Foucault argues that this self-application of the techniques aimed at caring, protecting, cultivating, and preserving its body from dangers and contacts necessitated an isolation of itself from other races to retain its differential value. This revealed how 'the bourgeoisie underscored the high political price of its body, sensations, and pleasures, its well-being and survival. To maximize the life of the whole nation, these techniques were eventually extended to lower classes, as a means of social control and political subjugation (Foucault, 1978: 123). This was a process by which the bourgeois established its hegemony, and, eventually, carried out its governmentality of dynamic racism (Foucault, 1978: 125). Social hierarchization, technologies of power and the self catered for constituently differential 
social groups, and government of the social as a whole, were achieved through the same process.

The governance pattern of our case study school reflected the power logic of State racism that Foucault articulates. In spite of a nominally bilingual education policy, prioritization of Chinese was a consensus among school people, which was also reflected in the school curriculum, an echo of the real intention of the government discourse unveiled earlier (also see Schluessel, 2007, 2009). Apart from the three minor courses (fuke), physical education, music, and fine art, plus the Uyghur language, that were permitted to be taught in Uyghur, the medium of instruction for all major courses (zhuke) in the minority department was stipulated as being Chinese. In addition, besides the textbooks of the Uyghur language and literature that were compiled in Uyghur, other textbooks were in Chinese. Furthermore, Zheng (2004) and Liang (2007) discover that the proportion of minority-related contents in the nationally uniform language textbooks was less than $2 \%$; and the textbooks of minority languages adopted in minority areas of bilingual education were bare translations of nationally uniform Chinese textbooks, with very little on minority heritage added to them. The message hidden is that the Uyghur language is useless in relation to socioeconomic development, an idea shared by the Han teachers and students we interviewed, especially in comparison with Chinese or English, demonstrating a hierarchized view of languages among Han interviewees. This view was directly associated with a concern about the status of the Han populace. Some students told us that 'we would be no longer like Han if we learnt Uyghur'. Some teachers further claimed that the status of the Uyghur would be enhanced if the Uyghur language was promoted, and ' that would be something]) we would not like to see happen'. It is thus unsurprising that both the school and teachers strictly forbade Uyghur students (mostly MKH students in the Chinese department, for whom Han teachers took full responsibilities) speaking Uyghur at school. A Han teacher shared her view with us:

If [I] heard a conversation in Uyghur, [I] would definitely condemn [the speakers]. You are MKH, [you come to school] to learn Chinese. If [you] want to speak Uyghur, go home or to the main campus. Our school leaders forbid [them] speaking [Uyghur], too. We all do not permit, and require that all of them [speak] Chinese ... Moreover, we have also communicated with their parents, [telling them], if [your children] want to learn Chinese, you'd better speak Chinese with them at home.

This undisguised hegemony and the way of disciplining language usage reveal that the Han did not think that Uyghur possessed value in the public domain, and should be confined to the home or private domain, or should even be marginalized at home too. This is likely to suggest a deep fear of the power of the Uyghur language, its capacity to shore up the Uyghur culture, and ultimately the Islamic religion. This idea was internalized by both Uyghur teachers and students to a large extent. Some MKH students did not think it was a shame that they did not learn Uyghur, and would even feel 'uncomfortable' to speak Uyghur. Meanwhile, both MKH and MKM students expressed 
explicitly their admiration of Han students, who, in their view, speak excellent Chinese (reads 'possess [more] merits'). This admiration was coupled by their lived experience of frustration with Chinese in their daily schooling, especially among MKM students. When sitting in the classroom of Grade One in the main campus, we observed that students could not understand simple directives their teacher gave in Chinese. Even in the classroom of Grade Five, the situation was not encouraging. We found that merely up to one-third of students could understand the teacher in Chinese. However, when the language of instruction was switched into Uyghur, students responded actively and enthusiastically. ${ }^{8}$ This issue seemed to arouse limited sympathy among teachers, even among Uyghur teachers. One Uyghur teacher described their co-ethnic students as 'little idiots' (xiao baichi), because 'most of MKM Uyghur families were from Southern Xinjiang (where Uyghur are highly concentrated)', whose parents 'have low educational levels'.

Low performance in language learning is a result of cultural discontinuity between family and school among Uyghur children, resulting in their lack of cultural capital (Bourdieu and Passeron, 1977; Ogbu, 1987). Cultural capital is not merely associated with language issues, but also related to the history and culture of the Uyghur. Han interviewees all objected to learning Uyghur culture or history. When the question was posed to Uyghur teachers in the way in which we asked whether their textbooks incorporated Uyghur-related contents, they cautiously responded: 'it would be fine as long as we teach textbook contents effectively'. Their cautious tone revealed their self protection as well as reserve. Quite different from their teachers, both MKM and MKH students we interviewed appeared to be less cautious and believed that it was necessary for them to learn their own religion and culture at school. These different comments reveal an important message; to rule out ethnic elements from the curriculum is not persuasively necessary or constructive; and, further, it may potentially invite a clash between Uyghur cultural customs and what government policy forbids. In our investigation, the dress code of Uyghur students became a target of strict discipline. The Secretary of the CCP of the school told us that:

We keep emphasizing at various meetings that (female) students are not allowed to wear a headscarf. You can barely find students wearing a headscarf on campus. Yet, if you walk out the campus after classes, you can find that girls will take their headscarf out of their pocket, and put it on. The parents of those girls require that they must wear a headscarf, especially those from Southern Xinjiang. We as a school will definitely never permit them to wear a headscarf. We sometimes behave like underground workers (dixia gongzuozhe) when attempting to prevent them from practicing religion.

8 This revealed there was some room left for flexibility in adopting the medium of instruction in practice despite the school policy requiring that Chinese was the language to be used in the classroom for major courses. 
This 'culture war' between school policy and Uyghurs' insistence was also proved by parents and teachers we interviewed. Grose (2015), in his study of Xinjiang Class graduates, interprets this phenomenon in terms of what Louis Althusser called the 'interpellation' of Uyghur students by both state ideology and non-state ideologies of Uyghur communities, showing why and how state ideology is challenged on various frontiers. The insistence of the school on the policy of separating religion from schooling by strictly controlling religious customs is an ingrained process in which a negative image of the Uyghur was created, that was particularly represented by the Uyghurs from Southern Xinjiang. This creation of a negative image is particularly observable in Han teachers' comparison of MKH and MKM Uyghur families. They thought it was impossible to see $\mathrm{MKH}$ students in a headscarf, simply because their parents received modern knowledge and values. Those in a headscarf are all 'from Southern Xinjiang', 'they barely know a little Chinese, and their heads are muddled [ naozi bei hu zhe ne]'. Meanwhile, in the eyes of Han teachers, their Uyghur colleagues of the MKM background 'have very low quality', such that they lack a sense of timing, responsibility and intellect. They employed more negative words to describe their MKM students as trouble makers, who were 'barbaric' (yeman), 'unreasonable' (bujiang daoli), 'undisciplined' (meiyou zhixu), and 'unhygienic' (meiyou weisheng xiguan). ${ }^{9}$

This comparison usually resulted in a moral hierarchization of normal and abnormal groups, an idea that State racism promotes. One Han teacher thought that the recently appointed young Uyghur teachers of MKH background were enthusiastic for teaching, because '[they] received more sinicized education [hanhua jiaoyu]'; 'they [thus] feel they are normal [zhengchang]. To receive [sinicized] education has made them realize [the abnormality of their own ethnic group].' These Uyghur teachers were viewed as normal because Han teachers thought that they 'are moving forward along with society [genzhe shehui zou]'. This favour of MKH Uyghurs by Han Chinese is generally observed by Taynen (2006). They are more desirably admitted into [Chinese] society in the form of political and employment advantages over their MKM counterparts as a result of their acquisition of some Han characteristics both culturally and linguistically (also see Smith Finley, 2007). 'Society' in this context, as Wetherell and Potter (1992) portray Pākehā positions in relation to the Māori in New Zealand, is exclusively reserved for the mainstream that possesses both civilization and a mundane, technical, and practical outlook. In this demarcation of normality and abnormality by the mainstream criteria, State racism carries out a civilizing project in a colonialist view of the cultural primitiveness and inferiority of the Other against the cultural complexity and superiority of the mainstream. This is what Harrell (1995: 15-17) portrays as the metaphor of history in conceptualizing civilization projects with respect to relationships between civilizers and civilized, that leads to the hierarchy of center-periphery or superior-inferior.

9 This type of inter-ethnic stereotypes are widely seen in China. For more information, see, e.g., Blum (2001), Kaltman (2007), Smith Finley (2013). 
Both Said's (1979) dissection of the process in which Orientalism gradually took shape in the West, and Butler's (2008) analysis of the torture in Abu Ghraib, reveal the same fact: how is a so-called 'Arab Mind' created through discourses and events that is meant to represent a 'pre-modern' mind in sharp contrast with the modern West. In doing so, the West aims at legitimating itself as the ultimate modern achievement, whilst at the same time constructing a negative image out of those counteracting against it. Butler (2008: 18) illustrates this creation as such a process: 'we embody that freedom, you do not; therefore, we are free to coerce you, and so to exercise our freedom, and you, you will manifest your unfreedom to us, and that spectacle will serve as the visual justification for our onslaught against you'. It was exactly in such an (internal) Orientalist way that a civilizationally undesirable and negative 'Uyghur Mind' was created as illustrated above, which consequentially endowed the school and teachers with legitimacy to discipline this Uyghur mind-image. An often observable example is that teachers believed that they had the right to discipline their Uyghur students with verbal or physical violence. In their view, violence would be the most effective technique to discipline 'violent' Uyghur students, and thus an appropriate way of civilizing Uyghurs. The example below illustrates vividly how a teacher 'justly' used violence to discipline Uyghur boys.

In a break between class sessions, we saw two Uyghur boys, Abliz and Eli (pseudonyms), who were fighting each other in the classroom, and a Han student, Haoliang, reported them to the form teacher, teacher Yuan. After arriving at the classroom in great anger, teacher Yuan started pulling the two boys harshly, and shouting at them: 'you two so much like fighting? [You really want to be] so barbaric? [Why not] keep fighting!' The two boys were then pulled by teacher Yuan to the office. After a while, the boys returned to the classroom with the teacher, who then pulled all MKM boys out of the classroom, and punched a boy called Turdi out of anger. Then teacher Yuan started scolding another boy Roza: 'It has been just a few days since you transferred [into this school], you started making trouble [zhao shi]! Today you tell your parents to come to school! You even did not pass the entrance exams, who do you think you are? You play [instead of studying] all the time! Ask your mother to take you back home [leave school]! [Look at you], such a big burly guy [ren gao ma da de].' The form teacher then turned to Diyar after a very short break: '[H]ow many bad habits [chou maobing] do you have? Tell your parent to come to school this afternoon, otherwise you will be suspended from classes.' Yuan then turned to Sultan, and reprimanded: '[Y] ou have too many bad habits! Tomorrow your father must come to school, must come at 11:0o o'clock! Look at you, you did not even copy your work correctly! I warn you, if you dare doodle [luan hua] again [on your exercise book], I will knock off your hand [ba nide shou qiaolan]! Then the doodled leaf was torn off by Yuan. 'You wear a pair of glasses, and pretend to be cultured [siwen], you think you look civilized [wenzhibinbin], knowledgeable [xuewen gao]? You have fallen behind seriously this semester! What a brilliant deskmate I arranged for you? Why did you not learn from him?' 
People of different ethnic groups were hierarchized through curriculum, discourse, and practice, which is a realization of state policy at the grassroots level towards ethnic minorities. This hierarchization has its consequences. It reinforces boundaries between different groups as a result of, on the one hand, making all subjects internalize this binary discourse of 'normality' and 'abnormality' as their cultural values, and, on the other, inviting and intensifying (a sense of) segregation between different groups. This is evidenced not only by ethnic segregation between the Uyghur and Han teachers recorded earlier, but also by students' attitudes towards inter-ethnic contact. In spite of their yearning for 'high quality' Han students, and willingness to make friends with their Han peers, as we were told, the message revealed in interviews with both Han and Uyghur students is a lack of willingness among Han students to have contact with MKM students. Moreover, Han students would not like to have contact with MKH students, either, despite them being 'slightly better' (hao yidian) than MKM students, in the words of Han students. Their explanation was that it is not very convenient [to have contact with MKH students]. [We] after all do not belong to the same ethnic group.' Surprisingly, this denial by Han students did not push MKH students to the side of MKM students to form an ethnic alliance. Quite the reverse, it made many $\mathrm{MKH}$ students believe that MKM students were truly 'too barbaric', 'not civilized', and reject contact with this group of co-ethnic fellows. Clearly, MKH students saw MKM students as an inferior enemy 'race' that supposedly may threaten the vulnerable health of their own 'race'. To become healthy or healthier, it was necessary to avoid contact with the abnormal, unhealthy, unpurified race of MKM students, even if (and because) they had little chance to have contact with presumably fully healthy, normal, and purified Han Chinese.

This idea of State racism was also found in the narratives of some MKM students. Although many MKM students expressed their willingness to make friends with Han students, they showed their great hesitation due to an inferiority complex over their own 'race', as Kamil, a 12-year-old migrant boy from Khotan, put it:

If [I] went to ask [Han students] for help with my study, I would feel very embarrassed [diulian]. If I did so, they [Han] would definitely think 'their level is so low'. We all have this kind of worry.

This self-abasement was actually created by the way Han students viewed Uyghur children as a harmful species that should be avoided rather than made friends with, as evidenced by an experience that ten-year-old Dildar, a female MKM student whose family was originally from rural Kashgar, had:

I do not have Han friends. I think they do not want to communicate [jiaoliu] with us. They are so afraid. In our neighborhood, there is one [Han kid], when [I said] I wanted to become friends with her, she immediately ran away.

These examples of maintaining the health and purity of one's own race were evidenced by the fact that many Han (and some MKH) students transferred to a Chinese school just before the merger because they wanted to avoid the 'bad influence' that (MKM) Uyghur would presumably have on them. We quote the evaluation by a Uyghur teacher as a summary of the consequences the merger school has on Uyghurs: 
The merger school has not had much effect on us [dui women yingxiang bu $d a]$. Whether we are merged or not, we feel like we do not have Han students around ... Han teachers have limited influence on minority children, nor do children of different ethnic groups have impact on each other.

The 'effect' this teacher was talking about here was a positive one between Uyghur and Han peoples that was absent from the merger school. In the meantime, the negative effect of the merger school on ethnic relationships was profound, as revealed throughout this paper. This is undoubtedly a potentially unsafe element threatening society that was, unfortunately, created by State racism at the national, local, and daily level via its attempt to design a safe environment primarily in its own interests.

\section{Conclusion and discussion}

In spite of a lack of information directly obtained from MKM boys about their own image, both the Han and the MKH agreed that MKM students, and especially MKM boys, always displayed a propensity for physical violence (especially against the Han Chinese). Some teachers and students of MKM background shared this view, too. We do not think this anti-school behavior is a phenomenon that occurred occasionally among MKM boys, and nor can it be isolated from the larger institutional picture. This is one of many consequences of the complex interaction between the Uyghur and the social system (through the mainstream agency of the school). The anti-school behavior is a self-defense strategy MKM Uyghur boys consciously or subconsciously have adopted against State racism's monopoly of the discursive framework.

Paul Willis portrays a highly similar case of British working class boys involved in 'self-damnation', that is intentionally failing by becoming trouble-makers at school. Willis (1977: 3) argues that 'this damnation is experienced, paradoxically, as truth learning, affirmation, appropriation, and as a form of resistance'. Yet, ' $\mathrm{t}$ ] he tragedy and the contradiction is that these forms of "penetration" are limited, distorted, and turned back on themselves, often unintentionally'. In Willis' eyes, his case study exemplifies the way in which the working-class culture is (re)produced via complex interaction between working-class boys and regulative state institutions.

Ferguson (2005: 316), in his analysis of a persistent school performance gap between blacks and whites in the USA, argues that this persistence is closely related to the ways in which whites and blacks have coped with and adapted to their respective positions in the nation's hierarchy of power and privilege, which reflect psychological self-defense mechanisms, social interaction patterns and disparities in access to opportunities. In our case study, Uyghur culture, language, and customs were regarded as being useless, or even harmful, to the safe development of society. Consequently, the school, as the agency of the state, to a large extent uprooted Uyghurs from their cultural-ecological environment via constraining their culture, language, and habitus; this resulted in the Uyghur becoming an excluded group from the 'normal' social body by denying a fully legitimate status to their culture and identities, and asserting a consequent need of normalization. This placed ethnically different school groups in hierarchically different 
positions in the school field, and different positions led to corresponding practices. In this condition, no matter who they were - 'barbaric' Uyghur boys or those who were willing to make friends with, or learn from, Han students; 'conservative' Southern Xinjiang Uyghur families, or MKH families that were 'moving forward along with society' - all were making their own decision in accordance with their perception of mainstream society, and their relational position in comparison to the latter. That is, they were all creating their own form of citizenship under the logic of making a difference against either their own ethnic heritage, or the mainstream institution. But how far, and in what way, can they go in their struggle for (more) room for the development of their activist (although not necessarily 'positive') citizenship?

In a recent talk, Agamben (2014) continues his idea by further suggesting that the state of exception is replaced by a permanent technology of government for security reasons. This technology shifts its focus from causes onto effects, because governing the causes is difficult and expensive, whereas effects only need to be checked and controlled. As a consequence, 'the normal relationship between the state and its citizens is defined by suspicion, police filing and control', and the unspoken principle underneath is that 'every citizen is a potential terrorist'. This has formed the very dialectics 'that tightly bind together terrorism and state in an endless vicious spiral'. Meanwhile citizens barely have a passive juridical status, which makes it difficult for them to construct a political and ethical identity. This state/citizen relationship is particularly pertinent in depicting the current situation in China, in which the state not only sets an increasing number of rules or standards for minority people to meet, and in fact for all citizens to meet, despite the degree to which they vary. These rules or standards are designed for checking and controlling effects without questioning causes of school 'failure' among certain students. This standardized design has not solved the problems as the designer expected; quite the reverse, it has created problems of school performance gaps in particular, and social injustice in general.

Agamben's pessimism is largely derived from his view of the passivity of citizens. Nonetheless, citizens are subjects capable of reflection and acts, even in the form of passively distancing themselves from the mainstream, as revealed by our case study or otherwise. ${ }^{10}$ Furthermore, as Isin (2009: 379) insightfully suggests, citizens are also capable of creating a scene to make a difference (rupture) against the script (order) designed by the state. Yet, citizens' capacity is strictly restrained in state-run sectors such as our case-study school, ${ }^{11}$ where state agencies exert Panopticist surveillance over citizens (Foucault, 1995). When this surveillance allows subjects nowhere to escape, it leaves them socially dead in public space (Orlando, 1982). Spaces where state agencies exercise less thorough surveillance are then be turned into sites for citizens to act. This

10 For instance, Grose (2015) illustrates vividly the way in which many Uyghur college students, after graduating from Xinjiang Classes where strict control is exerted over the open practice of Islam, began to cultivate personal piety to strengthen the sense of a distinct 'Uyghur' identity against the backdrop of Chinese mainstream society.

11 Also see note 10. 
is the very dynamism pushing more and more Uyghur 'terrorists' to riot, such as those which broke out in July 2009 in Urümchi between Uyghur and Han, and the car crash directly aimed at the most politically sensitive symbol of China, Tiananmen Square, in the autumn of 2013. These unsafe elements were in fact caused by the purifying project of State racism: the state's design of safe citizenship primarily in its own interests brings an unsafe sense among citizens, and thus insecure citizens act to make a difference, which results in the state feeling insecure, thus causing the creation of more exceptional 'camps'. As one setting for race purification, the school becomes a 'battlefield', where seesawing, antagonism, and conflict between State racism and especially the 'inferior' race (defined by the former) continue in the form of negative ethnic interaction.

When a positive interaction of a win-win game between the state and (particularly) its other 'race' of citizens, and between different ethnic groups, will arrive primarily depends on the extent to which, and the way in which, state power - that tends to turn citizens into homo sacer - is checked and restricted. This check and restriction is particularly urgent given the fact that modern Chinese sovereign power has been persistently privileged as a result of a desperate desire for state-strengthening initially triggered by imperial threat and internal disorder. This desire has been put into practice at the cost of traditionally 'individual rights, the rights of kin groups and religious communities, and local community self-government and autonomy' (Yang, 2011: 12). This sovereign power in contemporary China is seen to be growing even stronger to form a new pattern of governance that combines 'earlier Maoist socialism, nationalist and developmentalist practices and the discourses of the Communist Party with the more recent market logic', against which an oligarchic corporate state or neo-socialism is emerging (Dickson, 2007; Nonini, 2008: 145; Pieke, 2009).

Foucault (1988) points out a direction in which technologies of power and of the self intertwine to produce a positive and active subject. Is this achievable? Informed both by our empirical investigation and reflection upon it, and scholarship produced by others, we would propose a general principle that, in our belief, would make citizens active and enthusiastic towards state power as well as co-citizens: citizens must be viewed and treated as complex, delicate, and autonomous human beings, possessing Foucauldian technologies of the self, instead of subjects with a membership exclusively defined and manipulated by the biased power of State racism. This is a process of citizenship acquisition oriented by what Isin and Turner term a 'virtue ethic education', in the hope of the formulation of 'an important connection between virtuous citizens and effective and living institutions' (Isin and Turner, 2002: 7-8). This is a necessary learning process not only for citizens, but even more for the state.

\section{About the author}

Lin Yi has a Ph.D. in sociology from the University of Bristol, England, and is currently a professor of sociology at Xiamen University, China. Lin is the author of the monograph Cultural Exclusion in China: State Education, Cultural Difference and Social Mobility (Routledge 2008). His articles have appeared in such journals as 
The China Quarterly, British Journal of Sociology of Education, International Journal of Educational Development, Japanese Journal of Political Science, and Chinese Journal of Political Science, as well as Chinese scholarly journals. Lin's research primarily focuses upon the intersection between culture and politics, with particular reference to such issues as education, citizenship, ethnicity, migration, governmentality, and food. Lin is currently conducting a research project that looks into the connection between ethical self and citizenship.

\section{References}

Abdureşit, Jelil Q. and D. H. McMillen (2011), 'Towards a "Harmonious Society"? A Brief Case Study of the Post-Liberation Settlement in Beijing of Uyghur Intellectuals and Their Relations with the Majority Society', Asian Ethnicity, 12(1): 1-31.

Agamben, G. (1998), Homo Sacer: Sovereign Power and Bare Life, Stanford, CA: Stanford University Press.

Agamben, G. (2014), 'From the State of Control to a Praxis of Destituent Power', http://roarmag.org/2014/o2/agamben-destituent-power-democracy/ (accessed 6 February 2014).

Ba, Z. (2006), 'The Chinese Paradigm of the Multiethnic School: A Study of Merger Schools', Gansu Minzu Yanjiu, 2: 32-38.

Bellér-Hann, I. (2002), 'Temperamental Neighbours: Uighur-Han Relations in Xinjiang, Northwest China', in Günther Schlee (ed.), Imagined Difference: Hatred and the Construction of Identity, London: Palgrave Macmillan, pp. 57-81.

Blum, S. (2001), Portraits of Primitives: Ordering Human Kinds in the Chinese Nation, Oxford: Roman \& Littlefield.

Bourdieu, P. and J. Passeron (1977), Reproduction in Education, Society and Culture, Lois Wacquant (trans), London, Newbury Park, and New Delhi: Sage Publications.

Butler, J. (2008), 'Sexual Politics, Torture, and Secular Time', British Journal of Sociology, 59(1): 1-23.

Calhoun, Craig, Joseph Gerteis, James Moody, Steven Pfaff, and Indermohan Virk (eds.) (2012), Contemporary Sociological Theory, 3rd edn, Oxford: Wiley-Blackwell.

Chen, Y. (2008), Muslim Uyghur Students in a Chinese Boarding School: Social Recapitalization as a Response to Ethnic Integration, New York: Rowman \& Littlefield.

Cliff, T. (2012), 'The Partnership of Stability in Xinjiang: State-Society Interactions Following the July 2009 Unrest', The China Journal, 68: 79-105.

Dickson, B. (2007), 'Integrating Wealth and Power in China: The Communist Party's Embrace of the Private Sector', China Quarterly, 192: 827-54.

Ferguson, R. (2005), 'Why America's Black-White School Achievement Gap Persists', in Glenn Loury, Tariq Modood, and Steven Teles (eds.), Ethnicity, Social Mobility and Public Policy, Cambridge and New York: Cambridge University Press, pp. 309-41.

Foucault, M. (1978), History of Sexuality, vol. I, New York: Pantheon Books.

Foucault, M. (1991), 'Governmentality', in G. Burchell et al. (eds.), The Foucault Effects: Studies in Governmentality, University of Chicago Press, pp. 87-104.

Foucault, M. (1995), Discipline and Punish: The Birth of the Prison, 2nd edn, New York: Vintage Books.

Foucault, M. (2003), Society Must Be Defended, New York: Picador.

Foucault, M. (2009), Security, Territory, Population, New York: Picador.

Foucault, M. (1988), 'Technologies of the Self, in L. H. Martin, H. Gutman, and P. H. Hutton (eds.), Technologies of the Self: A Seminar with Michel Foucault, University of Massachusetts Press, pp. 16-49.

Grose, T. A. (2010), 'The Xinjiang Class: Education, Integration, and the Uyghurs', Journal of Muslim Minority Affairs, 30(1): 97-109.

Grose, T. A. (2015), '(Re)embracing Islam in Neidi: the 'Xinjiang Class' and the Dynamics of Uyghur EthnoNational Identity', Journal of Contemporary China, 24(91): 101-18.

Han, E. (2010), 'Boundaries, Discrimination, and Interethnic Conflict in Xinjiang, China', International Journal of Conflict and Violence, 4(2): 244-56. 
Hao, Y. and Liu, W. (2012), 'Xinjiang: Increasing Pain in the Heart of China's Borderland', Journal of Contemporary China, 21(74): 205-25.

Harrell, S. (1995), 'Introduction: Civilizing Projects and the Reaction to Them', in S. Harrell (ed.), Cultural Encounters on China's Ethnic Frontiers, Seattle and London: University of Washington Press, pp. 3-36.

Isin, E. (2009), 'Citizenship in Flux: The Figure of the Activist Citizen', Subjectivity, 29: 367-88.

Isin, E. and B. Turner (2002), 'Citizenship Studies: An Introduction', in E. Isin and B. Turner (eds.), Handbook of Citizenship Studies, London: Sage Publications.

Jiang, Y. (2002), 'A Preliminary Study of Merger Schools', Minzu Jiaoyu Yanjiu, 1: 16-19.

Kaltman, B. (2007) Under the Hell of the Dragon: Islam, Racism, Crime, and the Uighur in China, Athens: Ohio University Press.

Li, X. (2001), 'The Trajectory of Xinjiang Merger Schools and Its Future', Xinjiang Daxue Xuebao, 5: 22-8.

Liang, C. (2007), 'Cultural Reflection on Language Education of the Primary School in Minority Regions', Dangdai Jiaoyu Luntan, 3: 91-92.

Ma, Z. (2012), 'Ethnic Stratification in Xinjiang China: Structure and Mechanism', unpublished Ph.D. thesis of Beijing University.

Nonini, D. (2008), 'Is China becoming neoliberal?', Critique of Anthropology, 28(2): 145-76.

Ogbu, J. (1987), 'Variability in Minority School Performance: A Problem in Search of an Explanation', Anthropology and Education Quarterly, 18: 313-34.

Ong, A. (1996), 'Cultural Citizenship as Subject-Making: Immigrants Negotiate Racial and Cultural Boundaries in the United States', Current Anthropology, 37(5): 737-62.

Orlando, P. (1982), Slavery and Social Death: A Comparative Study, Cambridge, MA: Harvard University Press.

Pieke, F. (2009), 'The Production of Rulers: Communist Party Schools and the Transition to Neo-Socialism in Contemporary China', Social Anthropology, 17(1): 25-39.

Qian, M. (2009), A Real Xinjiang, Beijing: Renmin Chubanshe.

Said, E. (1979), Orientalism, New York: Vintage Books.

Schluessel, E. (2007), 'Bilingual' Education and Discontent in Xinjiang', Central Asian Survey, 26(2): 251-77.

Schluessel, E. (2009), 'History, Identity, and Mother-Tongue Education in Xinjiang', Central Asian Survey, 28(4): 383-402.

Smith, J. N. (2002), 'Making Culture Matter: Symbolic, Spatial and Social Boundaries between Uyghurs and Han Chinese', Asian Ethnicity, 3(2): 153-74.

Smith Finley, J. (2007), “Ethnic Anomaly” or Modern Uyghur Survivor?: A Case Study of the Minkanhan Hybrid Identity in Xinjiang', in I. Bellér-Hann et al. (eds.), Situating the Uyghurs between China and Central Asia, Farnham, UK: Ashgate, pp. 219-38.

Smith Finley, J. (2013), Uyghur Identities and Uyghur-Han Relations in Contemporary Xinjiang, Leiden: Brill.

Taynen, J. (2006), 'Interpreters, Arbiters or Outsiders: The Role of the Min kao Han in Xinjiang Society', Journal of Muslim Minorities, 26(1): 45-62.

Tsung, L. (2014), 'Trilingual Education and School Practice in Xinjiang', in James Leibold and Chen Yangbin (eds.), Minority Education in China: Balancing Unity and Diversity in an Era of Critical Pluralism, Hong Kong: Hong Kong University Press, pp. 161-86.

Urümchi Statistics Bureau (2011), Urümchi Statistics Yearbook 2011, Beijing: Zhongguo Tongji Chubanshe.

Wang, F. (2011), 'A Study of Income of Minority Migrants in Ürüchi', Zhonggong Wulumuqi Shiwei Dangxiao Xuebao, 4: 11-16.

Wang, J. (2000), 'Ethnically Related Residential Pattern and Ethnic Relationship in Ürümchi', Xibei Minzu Yanjiu, 1: 48 .

Wang, Y. (2010), 'Communication and Interaction between Uyghur and Chinese Students in Xinjiang: An Empirical Study in Urümchi', Beifang Minzu Daxue Xuebao, 2: 32-8.

Weber, C. (2008), 'Designing Safe Citizens', Citizenship Studies, 12(2): 125-42.

Wetherell, M. and Potter, J. (1992), Mapping the Language of Racism: Discourse and the Legitimation of Exploitation, New York: Columbia University Press.

Willis, P. (1977), Learning to Labor: How Working Class Kids Get Working Class Jobs, New York: Columbia University Press.

Yang, M. (2011), 'Postcoloniality and Religiosity in Modern China: The Disenchantments of Sovereignty', Theory, Culture and Society, 28(2): 3-44. 
Yee, H. S. (2005), 'Ethnic Consciousness and Identity: A Research Report on Uygur-Han Relations in Xinjiang', Asian Ethnicity, 6(1): 35-50.

Zang, X. (2011), 'Uyghur-Han Earnings Differentials in Urümchi', China Journal, 65: 141-55.

Zhang, H. (2005), 'A Study of Merger Schools in the Basic Education', unpublished Masters' thesis of Central Nationality University.

Zheng, J. (2004), Multicultural Education, Tianjin: Tianjin Jiaoyu Chubanshe.

Zuliyati, S. (2008), 'Ethnic Merger and Ethnic Segregation in School', Shehui Kexue Zhanxian, 6: 216-23.

Zuliyati, S. (2014), 'The Practice of Ethnic Policy in Education: Xinjiang's Bilingual Education System', in James Leibold and Chen Yangbin (eds.), Minority Education in China: Balancing Unity and Diversity in an Era of Critical Pluralism, Hong Kong: Hong Kong University Press, pp. 131-6o. 